\title{
Valorization of Rice Straw via Hydrotropic Lignin Extraction and Its Characterization
}

\author{
Chongxin Yin ${ }^{1}{ }^{\mathbb{D}}$, Min Wang ${ }^{1}$, Qingzhi Ma ${ }^{2}$, Huiyang Bian ${ }^{1} \mathbb{D}$, Hao Ren ${ }^{1}$, Hongqi Dai ${ }^{1}$ and Jinlan Cheng ${ }^{1, * \mathbb{C}}$ \\ 1 Jiangsu Co-Innovation Center for Efficient Processing and Utilization of Forest Resources, Jiangsu Provincial \\ Key Lab of Pulp \& Paper Science \& Technology, Nanjing Forestry University, Nanjing 210037, China; \\ yinchongxin1115@163.com (C.Y.); miminwang@126.com (M.W.); hybian1992@njfu.edu.cn (H.B.); \\ renhao@njfu.edu.cn (H.R.); daihq@njfu.com.cn (H.D.) \\ 2 Zhejiang Provincial Collaborative Innovation Center of Agricultural Biological Resources Biochemical \\ Manufacturing, Zhejiang University of Science and Technology, Hangzhou 310023, China; \\ maqingzhi@zust.edu.cn \\ * Correspondence: nfucjl@njfu.edu.cn
}

Citation: Yin, C.; Wang, M.; Ma, Q.; Bian, H.; Ren, H.; Dai, H.; Cheng, J.

Valorization of Rice Straw via

Hydrotropic Lignin Extraction and Its Characterization. Molecules 2021, 26,

4123. https://doi.org/

$10.3390 /$ molecules 26144123

Academic Editors: Jalel Labidi and Thomas Rosenau

Received: 30 April 2021

Accepted: 30 June 2021

Published: 6 July 2021

Publisher's Note: MDPI stays neutral with regard to jurisdictional claims in published maps and institutional affiliations.

\begin{abstract}
Rice straw hydrotropic lignin was extracted from $p$-Toluene sulfonic acid ( $p$-TsOH) fractionation with a different combined delignification factor (CDF). Hydrotropic lignin characterization was systematically investigated, and alkaline lignin was also studied for the contrast. Results showed that the hydrotropic rice straw lignin particle was in nanometer scopes. Compared with alkaline lignin, the hydrotropic lignin had greater molecular weight. NMR analysis showed that $\beta$-aryl ether linkage was well preserved at low severities, and the unsaturation in the side chain of hydrotropic lignin was high. $\mathrm{H}$ units and $\mathrm{G}$ units were preferentially degraded and subsequently condensed at high severity. High severity also resulted in the cleavage of part $\beta$-aryl ether linkage. ${ }^{31} \mathrm{P}$-NMR showed the decrease in aliphatic hydroxyl groups and the increasing carboxyl group content at high severity. The maximum weight loss temperature of the hydrotropic lignin was in the range of $330-350{ }^{\circ} \mathrm{C}$, higher than the alkaline lignin, and the glass conversion temperature $\left(\mathrm{T}_{\mathrm{g}}\right)$ of the hydrotropic lignin was in the range of $107-125^{\circ} \mathrm{C}$, lower than that of the alkaline lignin. The hydrotropic lignin has high $\beta$-aryl ether linkage content, high activity, nanoscale particle size, and low $T_{g}$, which is beneficial for its further valorization.
\end{abstract}

Keywords: $p$-Toluene sulfonic acid; lignin; rice straw; high valorization

\section{Introduction}

Rice straw is a byproduct of rice production and one of the most abundant, renewable, and low-cost agricultural wastes in the world. The general method that enterprises have adopted is burning, but it reduces the utilization value of lignin and causes some pollution to the environment [1,2]. Effective fractionation and full utilization of straw components can reduce environmental pollution and resource consumption [3-5]. Lignocellulosic biomass is primarily comprised of cellulose, hemicellulose, and lignin components. The lignin component is the second greatest inexhaustible natural organic polymer, and it represents more than $20 \%$ of the total mass of the Earth's biosphere [6]. The high valorization of lignin into the production of value-added chemicals is now recognized as a real challenge in terms of both sustainability and environmental protection. In a typical biorefinery, linocellulose is first fractioned by pretreatment, which is energy intensive, and predominantly focuses on producing high-quality cellulose. Many fractionation processes have been developed, such as alkaline, dilute acid, SPORL, organosolv, and $\mathrm{SO}_{2}$-catalyzed steam explosion, deep eutectic solvent, and other pretreatments [7-11]. Under these processing conditions the lignin is structurally modified, rending its further catalytic valorization very challenging [12]. Therefore, hydrotropic fraction is of great significance for finding a kind of pretreatment method that has relatively mild processing conditions and is beneficial for utilizing all components of the lignocellulose. 
Most works have focused on alkaline and kraft lignin [13,14], and hydrotropic lignin has only received attention in recent years. Hydrotropes are a class of amphiphilic molecules that cannot form well-organized structures, such as micelles, in water but do increase the aqueous solubility of organic molecules [15]. Hydrotropes increase the solubility of organic molecules in water by mediating the interactions between hydrophilic and hydrophobic molecules. p-tert-butylbenzenesulfonate, sodium cumenesulfonate, sodium $p$-toluenesulfonate, and 3,4-dimethylbenzenesulfonate are some commen hrdrotopes. $p$ Toluene sulfonic acid $(p-\mathrm{TsOH})$ is an efficient acid hydrotrope that can increase the solubility of hydrophobic substance lignin in the water phase $[16,17] . p-\mathrm{TsOH}$ hydrotropic fractionation is extensively studied due to environmentally friendly in terms of the ease separation, recovery and energy-efficient. $90 \%$ Lignin can be removed at $80{ }^{\circ} \mathrm{C}$ within $20 \mathrm{~min}$ at 80 $\mathrm{wt} \%$ of $p-\mathrm{TsOH}$, and the effect is equivalent to using a basic aqueous solvent to react for more than $10 \mathrm{~h}$ at a temperature of $\geq 150{ }^{\circ} \mathrm{C}$ or an alkaline method for $2 \mathrm{~h}$ at $150{ }^{\circ} \mathrm{C}$ [18]. The ability of hydrotropes to increase the solubility of organics in water is often strongest when the hydrotrope concentration is sufficient to induce the formation of associated structures. The concentration at which self-association begins is denoted as the minimum hydrotrope concentration (MHC). By diluting the spent liquor of $p$ - $\mathrm{TsOH}$ fraction with water to below the MHC $(12.5 \%)$, lignin can be precipitated $[19,20]$. The lignin obtained under mild reaction conditions has a light color, a low glass transition temperature, and a high $\beta$-aryl ether bond content [21]. When using a flow reaction instead of a batch reaction process, the results showed that the yield of lignin was as high as $80 \%$ [22]. $p$-TsOH can be reused after the steps of lignin precipitation, reconcentration, and dehydration of xylose into furfural. The $p$-TsOH after the reaction does not lose activity [23]. The low-temperature fractionation process could substantially reduce capital and operating costs for applications [24]. The characterization of rice straw hydrotropic lignin extracted from $p$ - $\mathrm{TsOH}$ was studied and compared with alkaline lignin. This study provides a theoretical basis for the high value-added utilization of rice straw.

\section{Results and Discussion}

\section{1. $p$-Ts $O H$ Fractionated Rice Straw Lignin}

A $p$-Toluene sulfonic acid $(p-\mathrm{TsOH})$ fractionation schematic is shown in Figure 1. Rice straw lignin obtained under the different conditions with $p$-TsOH concentration and temperature is shown in Figure 2. PxxTyytzz stands for fractionation under $p$ - $\mathrm{TsOH}$ concentration at $\mathrm{xx} \mathrm{wt} \%$ and $y y{ }^{\circ} \mathrm{C}$ for zz min. Reaction severity-based kinetic analysis was effective in predicting lignin dissolution in hydrotropic fractionation wood fractionation [21]. Studies have shown that acid pretreatment such as SPORL and $p-\mathrm{TsOH}$ fractionation can be divided into two stages: fast reaction and slow reaction $[25,26]$. The combined delignification factor $(\mathrm{CDF})$ can be used to evaluate and predict the lignin removal rate [27]. The CDF can be obtained by the Equations (1) and (2). Where $\mathrm{C}$ is the molar concentration of $p-\mathrm{TsOH}$ $(\mathrm{mol} / \mathrm{L}), \mathrm{R}$ is the universal gas constant, $8.314(\mathrm{~J} /(\mathrm{mol} \cdot \mathrm{K}))$, $\mathrm{t}$ is the reaction time $(\mathrm{min}), \mathrm{T}$ is the reaction temperature $(\mathrm{K})$, and $\mathrm{E}$ is the activation energy $(\mathrm{J} / \mathrm{mol}), \alpha$ and $\beta$ are fitting parameters, $\theta^{\prime}$ is the component of slow-reacting lignin, and $\mathrm{f}^{\prime}$ is the ratio of the reaction rate between slow to fast lignin. $\theta_{R}^{\prime}$ is the residual lignin. $L_{R}$ is the fractions of residual lignin in solids.

$$
\begin{gathered}
\mathrm{L}_{\mathrm{R}}=\left(1-\theta^{\prime}-\theta_{\mathrm{R}}^{\prime}\right) \mathrm{e}^{-\mathrm{CDF}}+\theta^{\prime} \cdot \mathrm{e}^{-\mathrm{f}^{\prime} \cdot \mathrm{CDF}}+\theta_{\mathrm{R}}^{\prime} \\
\mathrm{CDF}=\left[\exp \left(\alpha^{\prime}-\frac{\mathrm{E}^{\prime}}{\mathrm{RT}}+\beta^{\prime} \mathrm{C}\right)\right] \cdot \mathrm{C} \cdot \mathrm{t}
\end{gathered}
$$




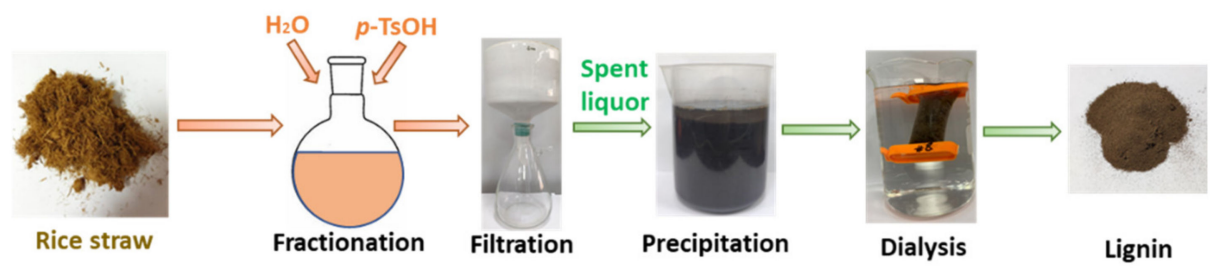

Figure 1. Experimental schematic flow diagram.

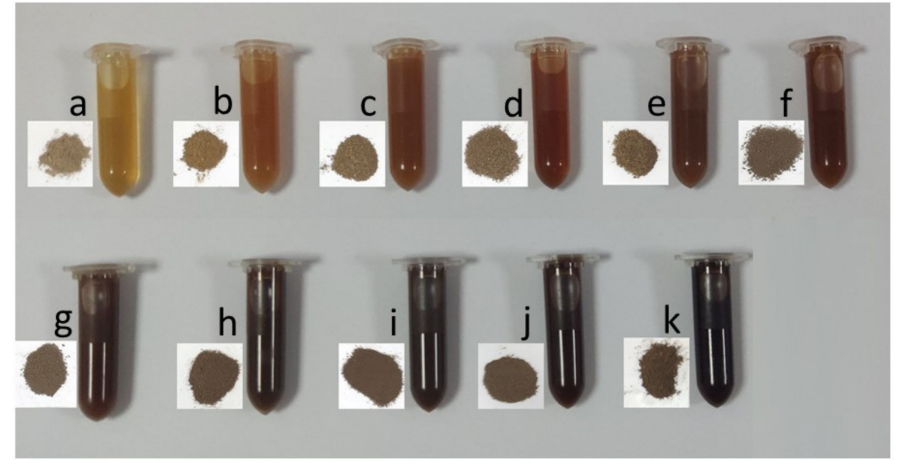

Figure 2. Pictures of $p$ - $\mathrm{TsOH}$ fractionated rice straw lignin and the spent liquor (in the bottles). (a) P20T70t60; (b) P45T60t45; (c) P30T70t45; (d) P60T60t30; (e) P30T80t30; (f) P45T70t30; (g) P60T70t15; (h) P45T80t15; (i) P45T70t60; (j) P45T80t60; (k) P60T80t45.

The CDF curve was obtained according to the degree of lignin removal in $p$-TsOH fractionated rice straw. The high value of CDF indicates high severity. Elevated fractionation temperature and ex-tended fractionation time resulted in more lignin removal. The lignin removal rate and CDF curves are presented in Table 1 and Figure 3 . The CDF at the inflection point of the curve is about 4000 .

Table 1. Rice straw lignin removal rate under a range of $p$-TsOH fraction conditions.

\begin{tabular}{cccccc}
\hline Sample & Concentration (\%) & Temperature $\left({ }^{\circ} \mathbf{C}\right)$ & Time $(\mathbf{m i n})$ & Lignin Removal Rate $(\mathbf{\%})$ & $\mathbf{C D F}(\mathbf{m i n} \cdot \mathbf{m o l} / \mathbf{L})$ \\
\hline P20T70t60 & 20 & 70 & 60 & 18.3 & 1134.7 \\
P45T60t45 & 45 & 60 & 45 & 31.4 & 1593.5 \\
P30T70t45 & 30 & 70 & 45 & 32.8 & 1638.9 \\
P60T60t30 & 60 & 60 & 30 & 37.5 & 2172.9 \\
P30T80t30 & 30 & 80 & 30 & 39.9 & 2396.0 \\
P45T70t30 & 45 & 70 & 30 & 40.2 & 2442.1 \\
P60T70t15 & 60 & 70 & 15 & 43.0 & 2497.6 \\
P45T80t15 & 45 & 80 & 15 & 43.1 & 2677.7 \\
P45T70t60 & 45 & 70 & 60 & 46.5 & 4884.3 \\
P45T80t60 & 45 & 80 & 45 & 50.4 & $10,710.8$ \\
P60T80t45 & 60 & 80 & 52.4 & $16,430.9$ \\
\hline
\end{tabular}




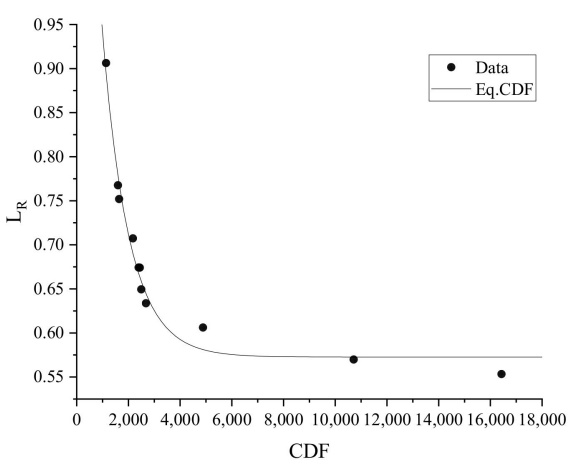

Figure 3. $\mathrm{CDF}$ curve of $p$-TsOH fractionation with rice straw.

\subsection{AFM Analysis}

AFM images and AFM topography of P45T70T60 (around the CDF curve inflection point) lignin sample are shown in Figure 4 . The mean height of lignin was about $8 \mathrm{~nm}$, and it was spherical. Nano lignin has a larger specific surface area and has great application value in the field of biomass functional materials. Recently, the development of nanoparticles (NPs) from lignin has gained interest due to its advantageous nature for drug delivery systems, delivery of hydrophobic molecules, improvement of the UV barrier, and as a reinforcing agent in nanocomposites, and its antibacterial and antioxidant applications. NPs developed from lignin have also been used as an alternative to inorganic NPs due to some safety issues raised in recent years [28-30].

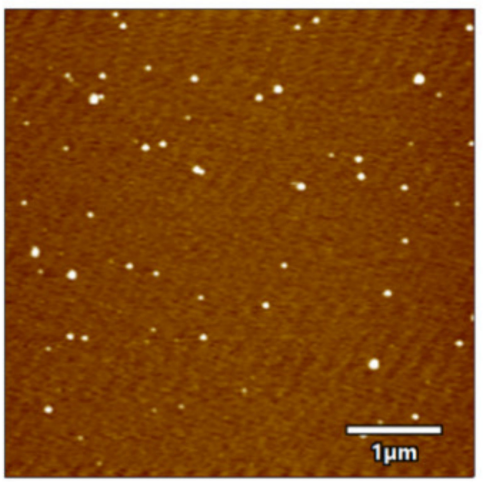

(a)

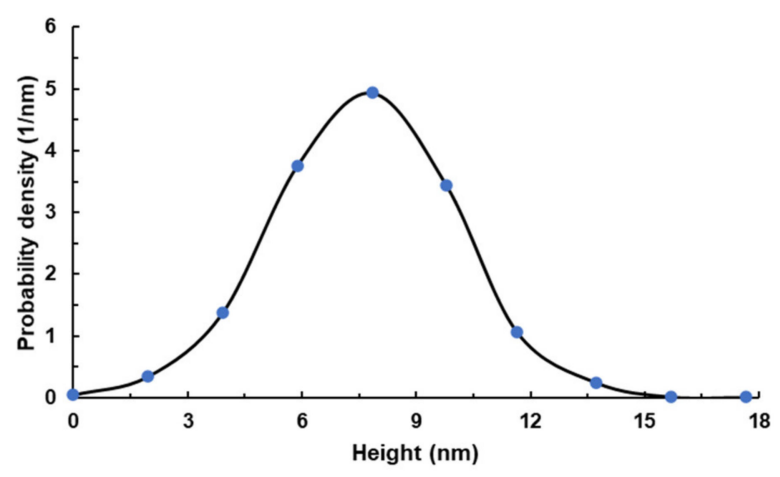

(b)

Figure 4. AFM images of lignin and height probability distribution profile: (a) P45T80t60 lignin image; (b) lignin height distribution profile.

\subsection{Particle Size Distribution of Lignin}

Hydrotropic lignin samples were chosen according to the CDF curve, which is circled in Figure 5a, including mild, medium, and severe severity. Average particle size of these lignin samples is ranged from 140 to $792 \mathrm{~nm}$. Fractionation severity affects lignin particle size. When the conditions were severe, the average particle size of lignin increased, and the particle dispersity also increased. The lignin particle is easy to flocculate in water, and the average particle size of lignin detected may not contribute to the single particle, but the lignin aggregate. 


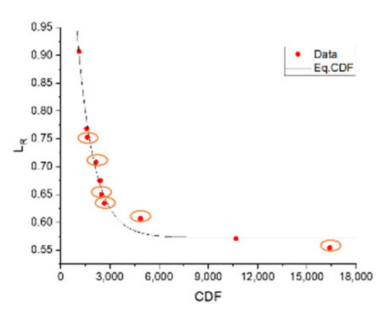

(a)

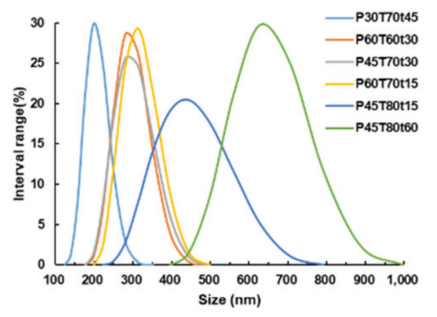

(b)

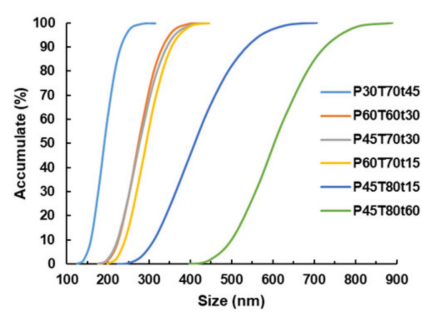

(c)

Figure 5. Size measurements of lignin: (a) The position of lignin obtained by $p$-TsOH fractionation on the CDF curve; (b) Distribution diagram of lignin particle size interval; (c) The cumulative distribution diagram of lignin particle size.

\subsection{Gel Permeation Chromatographic (GPC) Analyses}

The weight-average $(\mathrm{Mw})$ and number-weight $(\mathrm{Mn})$ molecular weights and polydispersity index (PDI) of the hydrotropic lignin and the alkaline lignin are shown in Table 2. The hydrotropic lignin had greater molecular weight, the $\mathrm{Mw}$ of hydrotropic lignin was all over 16,055 Da, the Mn was all over $2400 \mathrm{Da}$, and the PDI of hydrotropic lignin was greater than 3.9. The Mw of alkaline lignin was only $4397 \mathrm{Da}$, the Mn was $1428 \mathrm{Da}$, and the PDI was 3.08. During the reaction process, $\mathrm{NaOH}$ can break the ether bond between lignin molecules, so the lignin macromolecules degraded, and the molecular weight decreased. At low fractionation severity such as P30T80t30, with $\mathrm{Mw}=16055 \mathrm{Da}$ and PDI $=5.58$, the $\mathrm{Mw}$ of hydrotropic lignin decreased a little because of the partial degradation. The molecular weight decreased with the increased severity under fast reaction stages in the CDF curve. But at high severity in a slow reaction phase such as P60T80t45, the molecular weight increased because degraded lignin became condensed, $\mathrm{Mw}=12061 \mathrm{Da}$ and PDI $=5.00$.

Table 2. Mw, Mn and PDI of hydrotropic lignin and the alkaline lignin.

\begin{tabular}{cccc}
\hline Sample & Mw/Da & Mn/Da & PDI \\
\hline P30T80t30 & 16055 & 2876 & 5.58 \\
P30T70t45 & 13394 & 2671 & 5.01 \\
P45T80t15 & 10537 & 2576 & 4.09 \\
P45T70t30 & 11074 & 2587 & 4.28 \\
P45T60t45 & 14276 & 2882 & 4.95 \\
P60T70t15 & 11458 & 2550 & 4.49 \\
P60T60t30 & 10111 & 2593 & 3.90 \\
P60T80t45 & 12061 & 2413 & 5.00 \\
Alkaline lignin & 4397 & 1428 & 3.08 \\
\hline
\end{tabular}

\subsection{Chemical Structure and Functional Groups of the Hydrotropic Lignins}

The FTIR spectrum of the hydrotropic lignins is illustrated in Figure 6. The absorption peak positions of the main functional groups of different hydrotropic lignin did not change. The stretching vibration peak of $-\mathrm{OH}$ in the cellulose, hemicellulose, and lignin was at $3405 \mathrm{~cm}^{-1}$; it was a broad peak for lignin, and the absorption of lignins of high CDF (>4000) has low intensity, which means the hydroxyl groups decreased. At $2940 \mathrm{~cm}^{-1}$, there are CH stretching vibration absorption peaks of the methyl group, methylene group and methine group, and the absorption intensity varied a little as well [31,32]. At $1655 \mathrm{~cm}^{-1}$, there is the conjugated $\mathrm{C}=\mathrm{O}$ stretching vibration absorption peak, where the absorption peak is reduced, indicating that the relative content of p-hydroxy phenylpropane units is low. The peaks at $1510 \mathrm{~cm}^{-1}$ and $1460 \mathrm{~cm}^{-1}$ are assigned to the vibration of aromatic ring stretching. At $1356 \mathrm{~cm}^{-1}$, there are the $\mathrm{C}-\mathrm{H}$ bending vibration absorption peaks on the aromatic ring. Additionally, the absorption intensity of the two places does not change much. At $1263 \mathrm{~cm}^{-1}$, the $\mathrm{C}-\mathrm{O}$ bond stretching vibration absorption peaks in the aromatic ring methoxy group are very close together and in superposition to each other to form a 
wide peak because lignin contains both aromatic ethers, fatty ethers, and C-O structures in the carboxyl group. The in-plane and out-of-plane deformation of the benzene ring $\mathrm{C}-\mathrm{H}$ structure in the guaiacyl propane unit caused the absorption peaks of $1170 \mathrm{~cm}^{-1}$ and $873 \mathrm{~cm}^{-1}$, respectively.

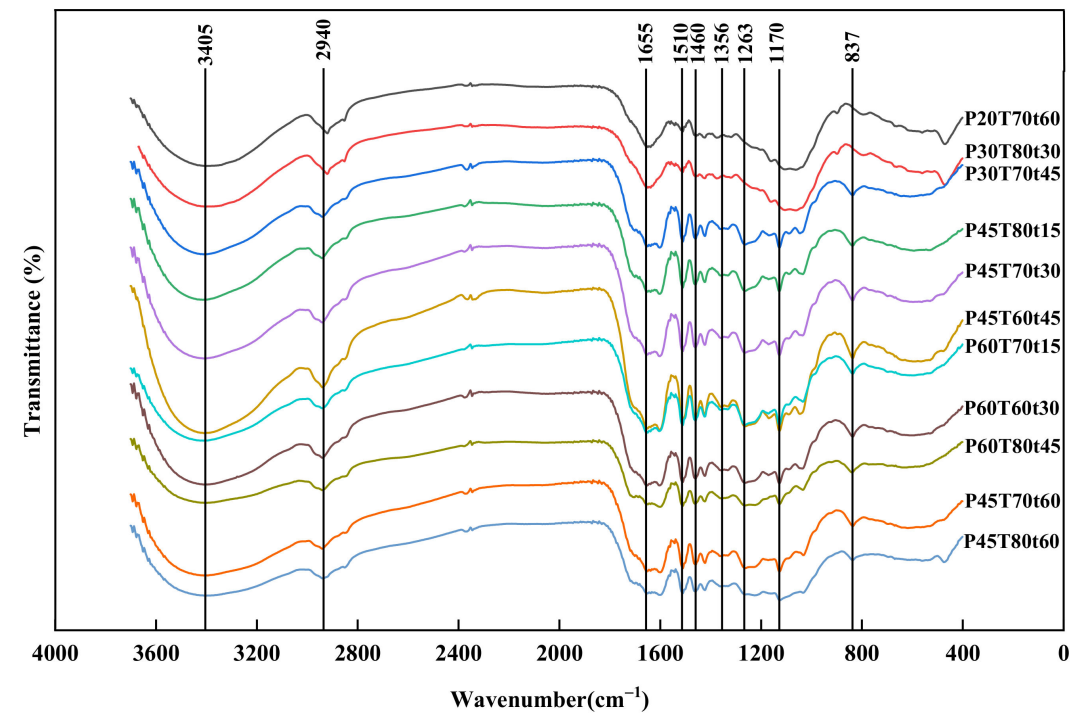

Figure 6. FT-IR spectra of lignin.

${ }^{31} \mathrm{P}$ NMR spectroscopy is illustrated in Figure 7. Since the signal peaks of the corresponding lignin in different hydroxyl structures in the ${ }^{31} \mathrm{P}$ NMR spectrum are well separated, and the chemical displacement is in significantly different regions, the characteristic functional groups such as phenolic hydroxyl, aliphatic hydroxyl, and carboxyl can be clearly distinguished in lignin. The positions of the absorption peaks of the lignin treated under different conditions are the same, but the absorption peak intensities are different. The signal peak of the aliphatic is $149.0-145.8 \mathrm{ppm}, 144.8-143.1 \mathrm{ppm}$ and $142.4-141.5 \mathrm{ppm}$ are the signal peaks of condensed $\mathrm{OH}, 143.1-142.4 \mathrm{ppm}$ is the signal peak of the syringyl unit (S), 140.0-138.8 ppm is the signal peak of the guaiacyl unit $(\mathrm{G}), 138.5-137.4 \mathrm{ppm}$ is the signal peak of the p-hydroxyphenyl unit $(\mathrm{H})$, and $136.0-133.8 \mathrm{ppm}$ is the signal peak of the carboxyl group. According to the results of nuclear magnetic detection, the higher CDF, the higher the content of carboxyl and condensed $\mathrm{OH}$, the higher the content of S-type and G-type lignin, the fewer aliphatic $\mathrm{OH}$, and the smaller the change in H-type lignin.

The content of $\mathrm{OH}$ and $\mathrm{COOH}$ in lignin was calculated as listed in Table 3 (in mmol/g lignin). The decrease in aliphatic hydroxyl groups suggested that the aliphatic $\mathrm{OH}$ groups were oxidized and modified during the $p$ - $\mathrm{Ts} \mathrm{OH}$ fractionation, such as the acid-catalyzed elimination reactions [26]. The high content of the phenolic hydroxyl implies the cleavage of $\beta-\mathrm{O}-4^{\prime}$ linkages [33]. P60T80t45's CDF was higher than others, and it also had a higher amount of phenolic $\mathrm{OH}$, suggesting that $p$-TsOH could break more $\beta-\mathrm{O}-4^{\prime}$ linkages and increase $\mathrm{S}$ and $\mathrm{G}$ phenolic hydroxyl groups at high $\mathrm{CDF}$. Lignin esterification by severe conditions increased the carboxyl group content in hydrotropic lignin.

Table 3. Quantification of the functional groups in lignin by ${ }^{31} \mathrm{P}$ NMR spectroscopy.

\begin{tabular}{|c|c|c|c|c|c|c|c|}
\hline \multirow{2}{*}{ Sample } & \multirow{2}{*}{$\begin{array}{c}\mathrm{CDF} \\
(\mathrm{min} \cdot \mathrm{mol} / \mathrm{L})\end{array}$} & \multirow{2}{*}{ Aliphatic $\mathrm{OH}$} & \multicolumn{4}{|c|}{ Phenolic OH (mmol/g) } & \multirow{2}{*}{$\mathrm{COOH}$} \\
\hline & & & Syringyl (S) & Guaiacyl (G) & p-Hydroxyl (H) & Condensed & \\
\hline P30T80t30 & 2396.0 & 2.51 & 0.13 & 0.44 & 0.40 & 0.31 & 0.69 \\
\hline P45T70t30 & 2442.1 & 2.67 & 0.14 & 0.47 & 0.44 & 0.32 & 0.52 \\
\hline P45T70t60 & 4884.3 & 2.16 & 0.13 & 0.42 & 0.35 & 0.29 & 0.69 \\
\hline P60T80t45 & $16,430.9$ & 1.73 & 0.21 & 0.50 & 0.40 & 0.50 & 0.88 \\
\hline
\end{tabular}




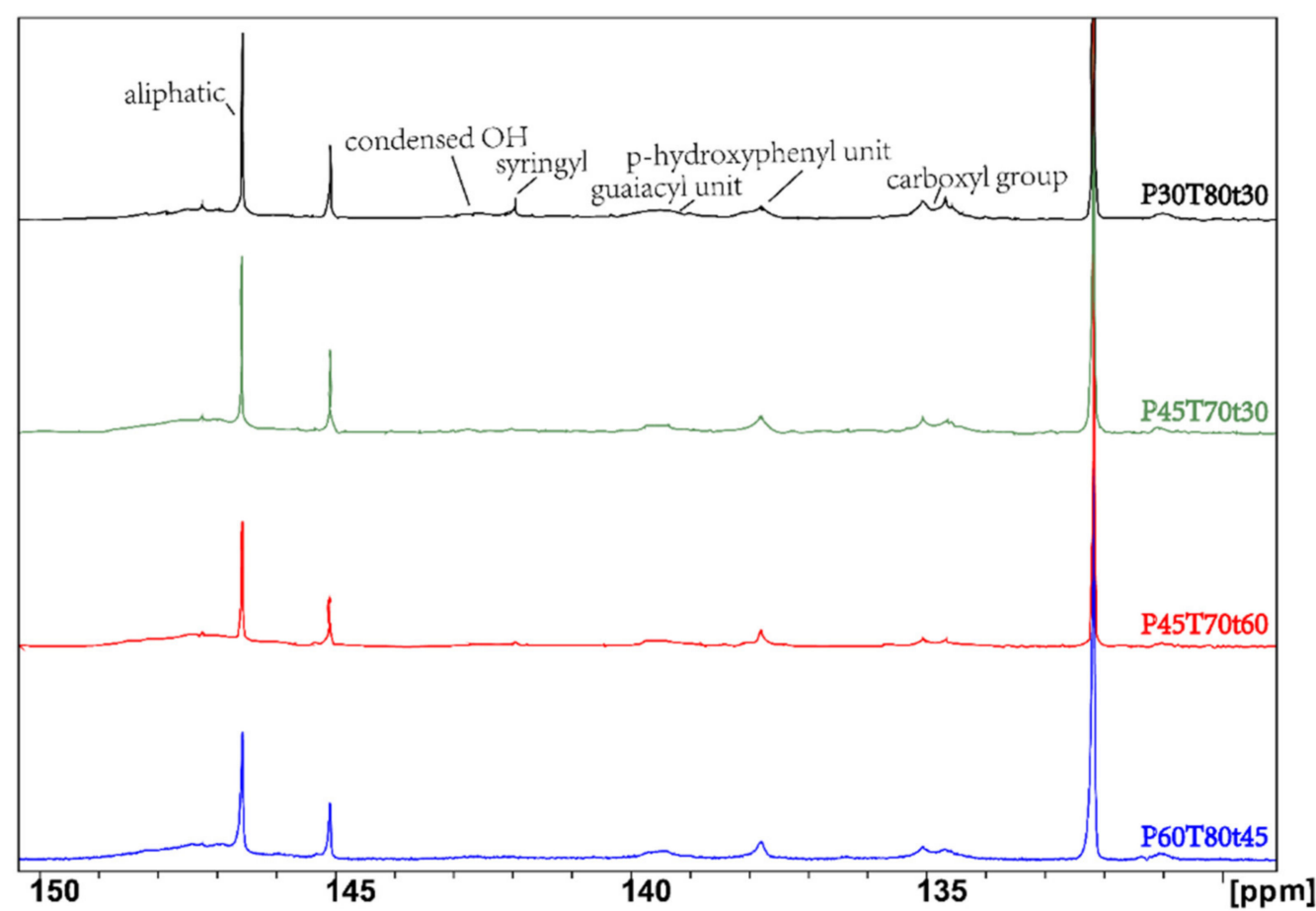

Figure 7. ${ }^{31} \mathrm{P}$ NMR spectroscopy of selected lignin samples in comparison. From top to bottom: P30T80t30, P45T70t30, P45T70t60, P60T80t45.

The main signals and substructures of lignin in the side chain $(\delta \mathrm{C} / \delta \mathrm{H} 50-90 / 2.5-6.0)$ and the aromatic region $(\delta \mathrm{C} / \delta \mathrm{H} 90-150 / 6.0-8.0)$ are shown in Figure $8.2 \mathrm{D}^{13} \mathrm{C}-{ }^{1} \mathrm{H}$ HSQC NMR can determine specific carbon functionalities that cannot be identified using either ${ }^{13} \mathrm{C}$ or ${ }^{1} \mathrm{H}$ one dimensional spectra [34-36]. The assignments of main cross-signals of lignin and quantification of main chemical structures per 100 monomeric lignin units (100 Ar) are based on literature [36-39]. The quantification of main chemical structures per 100 monomeric lignin units (100Ar) and ratio, and linkages content was calculated as listed in Table 4. Integration of $\mathrm{pCA}_{2 / 6}$ was used for the quantification of pCA content; the integration of the $\mathrm{FA}_{2}$ crosspeak was used for quantitation of FA content.

Table 4. Semi-quantitative analysis of lignin units and ratio, and linkages based on 2D-HSQC spectra.

\begin{tabular}{lcccccccccc}
\hline Sample & S & $\mathbf{S}^{\prime}$ & $\mathbf{G}$ & $\mathbf{G}^{\prime}$ & $\mathbf{H}$ & $\mathbf{F A}$ & $\mathbf{p C A}$ & $\mathbf{A}$ & $\mathbf{B}$ & S/G \\
\hline P30T80t30 & 26.93 & 3.63 & 44.29 & 13.73 & 11.43 & 3.50 & 16.92 & 31.44 & 1.51 & 0.53 \\
P45T70t30 & 30.56 & 1.59 & 36.09 & 19.06 & 12.70 & 2.98 & 19.83 & 33.97. & 2.21 & 0.58 \\
P45T70t60 & 32.96 & 0.83 & 34.97 & 18.67 & 12.58 & 2.58 & 14.65 & 29.81 & 2.17 & 0.63 \\
P60T80t45 & 32.53 & 0.00 & 26.28 & 8.24 & 32.95 & 0.64 & 10.94 & 15.34 & 0.00 & 0.94 \\
$\begin{array}{l}\text { Milled wood } \\
\text { lignin [40] }\end{array}$ & 26 & NA & 65 & NA & 9 & 4 & 32 & 56 & 2 & 0.4 \\
$\begin{array}{l}\text { Alkali oxygen } \\
\text { lignin [40] }\end{array}$ & 23 & NA & 50 & NA & 27 & 4 & 1 & 7 & 1 & 0.5 \\
\hline
\end{tabular}



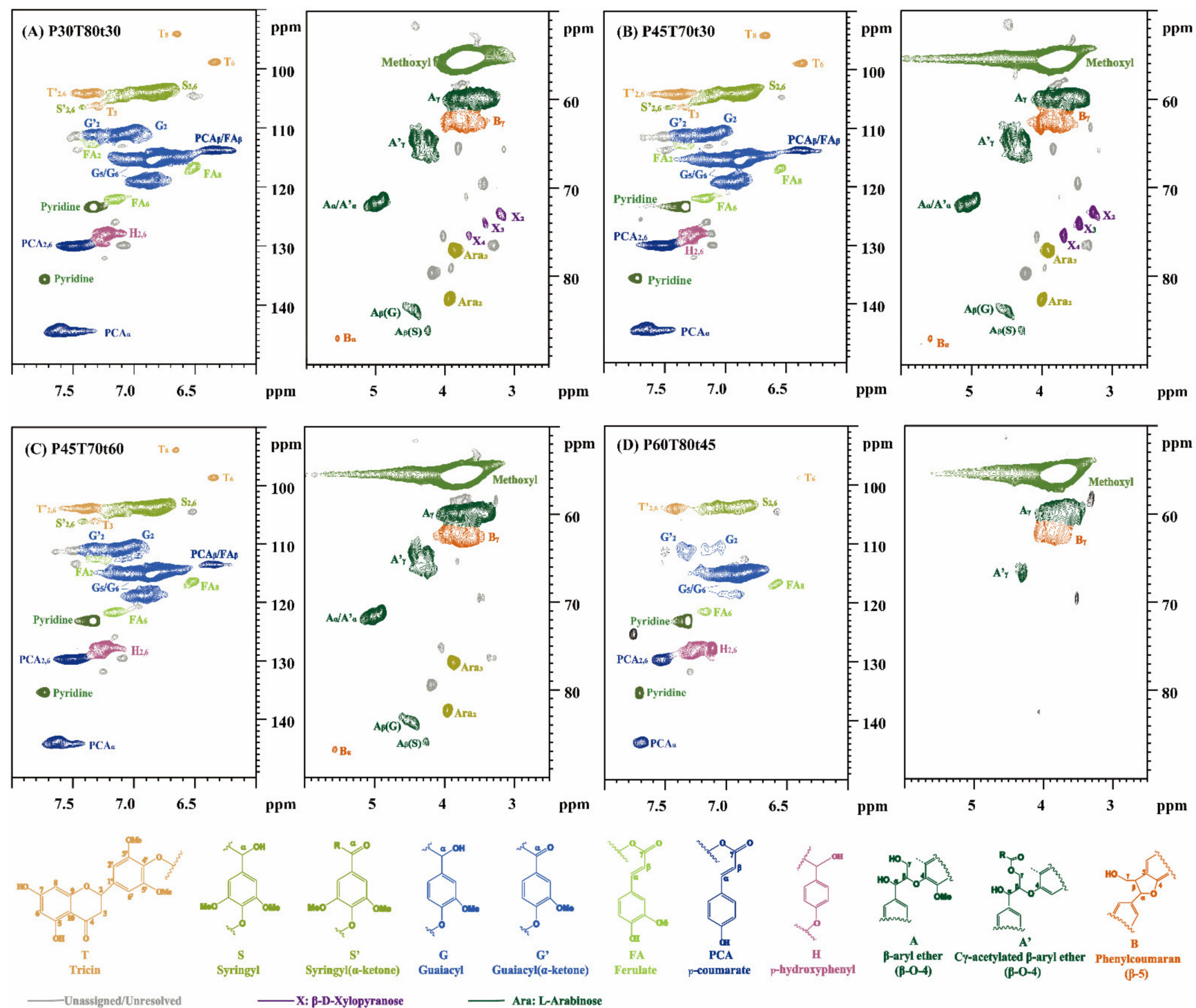

Figure 8. $2 \mathrm{D}{ }^{13} \mathrm{C}-{ }^{1} \mathrm{H}$ NMR HSQC spectra of selected lignin samples: (A) P30T80t30; (B) P45T70t30; (C) P45T70t60; (D) P60T80t45.

The total aromatic areas are defined as:

$$
\mathrm{I}(\mathrm{C} 9)=0.5 \times \mathrm{I}\left(\mathrm{S}_{2,6}\right)+0.5 \mathrm{I}\left(\mathrm{S}_{2,6}^{\prime}\right)+\mathrm{I}\left(\mathrm{G}_{2}\right)+\mathrm{I}\left(\mathrm{G}_{2}^{\prime}\right)+0.5 \times \mathrm{I}\left(\mathrm{H}_{2,6}\right) \text {. }
$$

The content of internal linkages is calculated as:

$$
\begin{aligned}
\beta-\mathrm{O}-4 & =100 \times[\mathrm{I}(\beta-\mathrm{O}-4)] /[\mathrm{I}(\mathrm{C} 9)] . \\
\beta-\beta & =100 \times[\mathrm{I}(\beta-\beta)] /[\mathrm{I}(\mathrm{C} 9)] . \\
\beta-5 & =100 \times[\mathrm{I}(\beta-5)] /[\mathrm{I}(\mathrm{C} 9)] .
\end{aligned}
$$

The content of aromatic units is relative (\%):

$$
\begin{gathered}
\mathrm{S}=100 \times 0.5 \times\left[\mathrm{I}\left(\mathrm{S}_{2,6}\right)\right] /[\mathrm{I}(\mathrm{C} 9)] . \\
\mathrm{S}^{\prime}=100 \times 0.5 \times\left[\mathrm{I}\left(\mathrm{S}_{2,6}^{\prime}\right)\right] /[\mathrm{I}(\mathrm{C} 9)] . \\
\mathrm{G}=100 \times\left[\mathrm{I}\left(\mathrm{G}_{2}\right)\right] /[\mathrm{I}(\mathrm{C} 9)] .
\end{gathered}
$$




$$
\begin{gathered}
\mathrm{G}^{\prime}=100 \times\left[\mathrm{I}\left(\mathrm{G}_{2}^{\prime}\right)\right] /[\mathrm{I}(\mathrm{C} 9)] \times 100 . \\
\mathrm{S}: \mathrm{G}=\left[\left(\mathrm{S}+\mathrm{S}^{\prime}\right)\right] /\left[\left(\mathrm{G}+\mathrm{G}^{\prime}\right)\right] .
\end{gathered}
$$

The side chain region of lignin mainly contains methoxyl (OMe), $\beta-\mathrm{O}-4^{\prime}$ linkages and carbohydrates, etc. OMe is accompanied by $\mathrm{G}$ or $\mathrm{S}$ structural units [41]. Correlation peaks from methoxyl groups and $\beta-\mathrm{O}-4^{\prime}$ linkages (A) were most prominent in the side chain region of all lignin preparations, followed by phenylcoumarans (B). Various signals associated with carbohydrates were also present, including $\beta$-D-xylopyranoside units $(X)$ and arabinofuranoside units (Ara). The typical signals for major intercellular connections in the side chain region of lignin are mainly from the structure of $\beta-O-4^{\prime}, \beta-5^{\prime}$ and $\beta-\beta^{\prime}[16,26]$. The signals at $\delta \mathrm{C} / \delta \mathrm{H} 71.5 / 5.00 \mathrm{ppm}, 83.8 / 4.48 \mathrm{ppm}$, and 59.9/3.63 ppm are attributed to $\mathrm{A} \alpha, \mathrm{A} \beta(\mathrm{G})$, and $\mathrm{A} \gamma$ correlation in $\beta-\mathrm{O}-4^{\prime}$ substructures, respectively.

This indicated that temperature played a more critical role than acid concentration. For example, lignin from the two runs with moderate temperatures and fraction time: the $\beta-\mathrm{O}-4^{\prime}$ linkages content of P45T70t30, P30T80t30, and P45T70t60 varied little; it was around $30 \%$. But P60T80t45 $\beta$-O- $4^{\prime}$ linkage content was only $15.34 \%$, approximately $50 \%$ of $\beta-\mathrm{O}-4^{\prime}$ linkages content was reduced compared to P30T80t30 lignin. This indicates that high temperature, elevated concentration, and extended fractionation duration play a critical role in eliminating $\beta-\mathrm{O}-4^{\prime}$ linkages to form condensed lignin. The pretreatment enhances the degradation of lignin as the severity increases. The $\beta-\mathrm{O}-4^{\prime}$ linkages content of alkali oxygen lignin was only 7\%, even lower than the P60T80t45 lignin [40].

The $\mathrm{B} \gamma$ signal appeared in the side chain region, and the B linkage content was much lower than the A linkage, which may be because the B structure was more stable and difficult to extract by $p$-TsOH. The side chains of coumaric acid, ferulic acid, and tritice all contain an active olefin $(C \alpha=C \beta)$ structure, and the olefin content reflects the reactivity of lignin to a certain extent. The absorption peak of side chain olefins was in the benzene ring region of lignin. The olefin content was expressed by the number of olefin carbon (VC) in 100 aromatic rings (100 Ar) [37]. The number of vinylic carbons was quantified using equation 12. The results (Table 5) showed that the VC/100 Ar content was 68.5(P30T80t30), 45.4 (P45T70t30), 35.0 (P45T70t60), and 21.1(P60T80t45), respectively. The $\mathrm{VC} / 100$ Ar content of milled wheat straw lignin was about 25 [42]. which indicated that the unsaturation in the side chain of hydrotropic lignin was high. The hydrotropic lignin had high reactivity. But the reactivity decreased with the increasing CDF.

$$
\mathrm{VC} / 100 \mathrm{Ar}=2\left(\mathrm{I}_{\mathrm{FA} \alpha}+\mathrm{I}_{\mathrm{pCA} \alpha}+\mathrm{I}_{\mathrm{T} 3}\right) /\left[\mathrm{I}(\mathrm{C} 9)+\mathrm{I}_{\mathrm{FA} 2}+\left(\mathrm{I}_{\mathrm{T}^{\prime} 2,6}+\mathrm{I}_{\mathrm{pCA} 2,6}\right) / 2\right] \times 100
$$

Table 5. The number of olefin carbon (VC) calculation.

\begin{tabular}{lccccccc}
\hline Sample & $\mathbf{I}(\mathbf{C 9 )}$ & $\mathbf{I}_{\mathbf{F A} \boldsymbol{\alpha}+} \mathbf{I}_{\mathbf{p C A} \boldsymbol{\alpha}}$ & $\mathbf{I}_{\mathbf{T} \mathbf{3}}$ & $\mathbf{I}_{\mathbf{T}^{\prime} \mathbf{2}, \mathbf{6}}$ & $\mathbf{I}_{\mathbf{F A 2}}$ & $\mathbf{I}_{\mathbf{p C A 2 , 6}}$ & $\mathbf{V C / 1 0 0 A r}$ \\
\hline P30T80t30 & 0.113 & 0.0308 & 0.0165 & 0.0046 & 0.004 & 0.0382 & 68.4 \\
P45T70t30 & 0.104 & 0.0277 & 0.0031 & 0.0162 & 0.0031 & 0.0412 & 45.4 \\
P45T70t60 & 0.097 & 0.0201 & 0.0012 & 0.0158 & 0.0025 & 0.0284 & 35 \\
P60T80t45 & 0.07 & 0.0091 & 0 & 0.0154 & 0.0009 & 0.0154 & 21.1 \\
\hline
\end{tabular}

The aromatic region of rice straw lignin was mainly composed of the basic structural units of $\mathrm{H}, \mathrm{G}$ and $\mathrm{S}$ lignin. This indicates that rice straw cell walls were mainly enriched with $G$ and $S$ units along with a minor amount of hydroxyphenyl units. The signals that corresponded to p-coumarate (pCA) and ferulate (FA) structures were also observed clearly in the aromatic region. The $\mathrm{G}$ and $\mathrm{S}$ units were the main structures in rice straw. The signals derived from tricin (T) were also detected in the HSQC NMR aromatic region. Generally, the pretreatment efficiency is directly proportional to the amount of $S$ units in the lignin [43]. The amount of $\mathrm{H}$ unit and $\mathrm{G}^{\prime}$ unit increased after high severity treatment, while the $\mathrm{S}$ unit decreased. The $\mathrm{G}$ units have a free $\mathrm{C}-5$ position available for carbon-carbon bonds, which makes them relatively resistant to lignin depolymerization in pretreatment $[44,45]$. $\mathrm{H}$ units 
have a free $\mathrm{C}-3$ and $\mathrm{C}-5$ position available for carbon-carbon bonds. Moreover, the slight increase in the $S / G$ ratio indicates that the $G$ units were preferentially degraded. At low fractionation severities such as P30T80t30, P45T70t30, and P45T70t60, the $S$ to $G$ ratio and $\beta-\mathrm{O}-4$ varied little, suggesting that the lignin structure was not significantly altered. The signal intensities of the PCA and FA were decreased with the increasing CDF. This suggests that the hydrotropic process could decompose the p-coumaric acid and ferulate structure.

\subsection{Thermal Characteristics of Lignin}

Thermal characteristics of lignin can be obtained from thermos-gravimetry analysis (TGA) and differential scanning calorimeter (DSC). These analyses give useful data on specific temperatures where various heterogeneous reactions occur throughout the pyrolysis of biomass inside the TGA. TG and DTG profiles are shown in Figure 9. The thermal stability of lignin can be expressed by the maximum weight loss rate of lignin [31,32]. The maximum weight loss temperature of the hydrotropic lignin is basically in the range of $330-350{ }^{\circ} \mathrm{C}$; this is due to the complex structure of lignin with phenolic hydroxyl and carbonyl groups and benzylic hydroxyl. The thermal degradation rate of the hydrotropic lignin showed a rapid upward trend in the range of $120-350{ }^{\circ} \mathrm{C}$, and then gradually decreased as the temperature increased. The maximum weight loss temperature of P60T80T45 lignin was the highest at $352{ }^{\circ} \mathrm{C}$. The maximum weight loss of the alkaline lignin had two peaks, the first thermal degradation rate was $0.13 \% \cdot{ }^{\circ} \mathrm{C}^{-1}$ at $200{ }^{\circ} \mathrm{C}$, the second thermal degradation rate was $0.13 \% \cdot{ }^{\circ} \mathrm{C}^{-1}$ at $377^{\circ} \mathrm{C}$. These results indicated that the hydrotropic lignin is harder to be decomposed than the alkaline lignin.

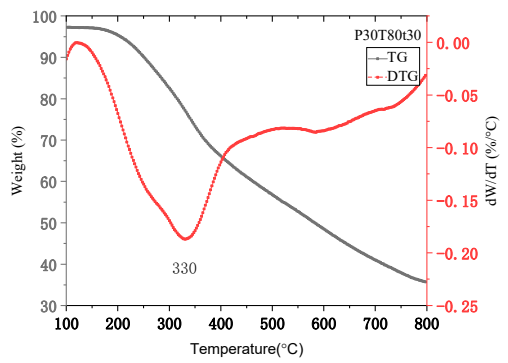

(a)

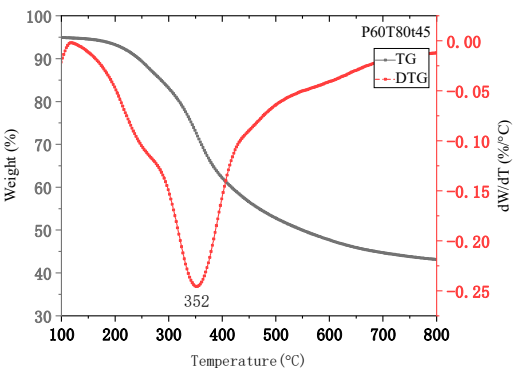

(c)

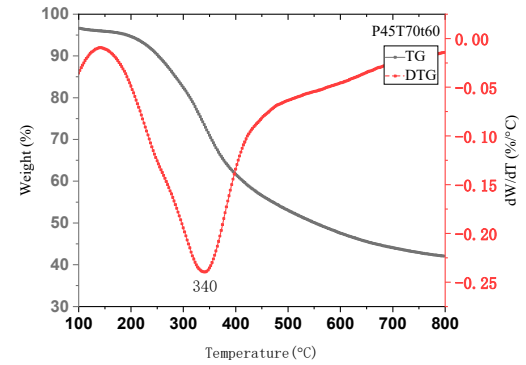

(b)

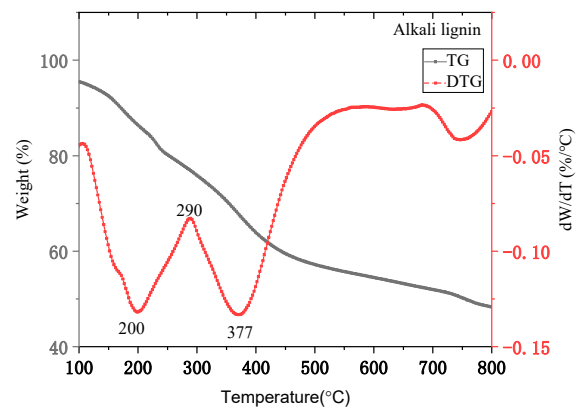

(d)

Figure 9. TG and DTG profile of selected lignin samples: (a) P30T80t30; (b)P45T70t60; (c) P60T80t45; (d) Alkali lignin.

The DSC curve can reflect the thermal effect of lignin. The glass conversion temperature $\left(\mathrm{T}_{\mathrm{g}}\right)$ of the hydrotropic lignin was in the range of $107-125^{\circ} \mathrm{C}$ (Figure 10$) . \mathrm{T}_{\mathrm{g}}$ of the hydrotropic lignin increased a little with increasing severity. This may also indicate lignin condensation at high CDF. The glass transition temperature of alkaline lignin was $130^{\circ} \mathrm{C}$, higher than that of the hydrotropic lignin. Because the alkaline lignin was structurally modified under high temperature pretreatment, the low $\mathrm{T}_{\mathrm{g}}$ of hydrotropic lignin, the low 
condensation degree, and higher activity was beneficial for its further catalytic or other valorization.

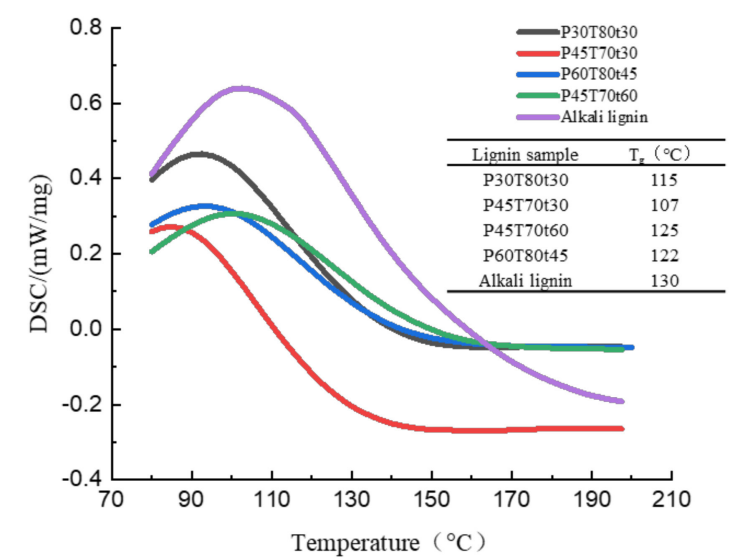

Figure 10. DSC profile and $\mathrm{T}_{\mathrm{g}}$ of lignin samples.

\section{Materials and Methods}

\subsection{Chemicals}

Rice straw was collected from Yancheng, Jiangsu Province, China. It was run through with a disk refiner, only one pass without any chemical treatment. The moisture of rice straw filament was approximately $10 \%$. The $p$-TsOH ( $\geq 99.5 \%, \mathrm{AR})$ was purchased from Shanghai Macklin Biochemical co Ltd., Shanghai. China.

\section{2. $p$-TsOH Fractionation and Alkali Fractionation of Rice Straw}

$p$-TsOH fractionation was carried out according to the experimental flow schematics shown in Figure 1. For each fractionation, an acid solution to rice straw ratio of 10:1 was used (i.e., $20 \mathrm{~g}$ oven-dry (OD), and rice straw was fractionated in $200 \mathrm{~g}$ of the $p$-TsOH solution [21]). Fractionation runs were conducted in a $500 \mathrm{~mL}$ flask heated to the desired fractionation temperature by water bath. At the end of the preset time, $200 \mathrm{~mL}$ DI water was added to dilute the acid concentration to terminate the fraction. The solids and spent liquor were separated using vacuum filtration with the Whatman filer paper. Spent liquor was diluted to $2 \%$ acid concentration with water to precipitate the hydrotropic lignin. After settling for $24 \mathrm{~h}$, the supernatant was decanted and the precipitate lignin was collected. To remove the remaining $p$ - $\mathrm{TsOH}$, the collected lignin was dialyzed using DI water until conductance reached $1 \mu \mathrm{S} / \mathrm{cm}$ as measured by a conductance meter (DDS-307, Shanghai INESA Scientific Instrument Co.,LTD, Shanghai. China). The lignin was then freeze-dried for further use.

Alkali fractionation: The rice straw was cooked using $10 \% \mathrm{NaOH}$ in an oil bath rotary digester with a material to liquid ratio of 1:4. Impregnation and mixing were performed for $15 \mathrm{~min}$, and rice straw was then cooked at $150{ }^{\circ} \mathrm{C}$ for $2 \mathrm{~h}$, which included $1.5 \mathrm{~h}$ required to raise the temperature of the digester from room temperature to the cooking temperature of $150{ }^{\circ} \mathrm{C}$. The cooked pulp and black liquor were separated with a 200 mesh cloth bag, and the pulp was washed thoroughly. Lignin in black liquor was precipitated by adjusting $\mathrm{pH}$ to 2 with $0.5 \mathrm{~mol} / \mathrm{L} \mathrm{HCl}$ and stirring for $1 \mathrm{~h}$ at room temperature. The crude lignin dissolved in $90 \%(w / w)$ acetic acid, and the soluble fraction was slowly introduced into deionized water. The precipitate was washed with deionized water thoroughly, and then was freeze-dried to obtain AL [40].

\subsection{Atomic Force Microscopy (AFM) Analysis}

A $0.1 \%$ lignin suspension was sonicated for $30 \mathrm{~min}$. A drop of the suspension was dispersed on a mica substrate, air-drying at ambient temperature [20]. Atomic Force Microscopy (AFM, Bio MFP-3D, Asylum Research, USA) images of the air-dried lignin 
were taken in vibrating tapping mode using the manufacturer's protocol. The height distributions of lignin from the AFM-measured topography of the sample were analyzed using the commercial software.

\subsection{Particle Size Measurement}

Lignin particle size distribution was measured at photon number $40-60 \mathrm{~K}$ with a nanometer laser particle size analyzer (BT-90, Bettersize Instruments Ltd., Dandong China).

\subsection{Gel Permeation Chromatographic (GPC) Analysis}

The lignin samples were acetylated before GPC analysis. In brief, $0.1 \mathrm{~g}$ of lignin was dissolved in $2 \mathrm{~mL}$ of mixed solution (pyridine and acetic anhydride $v: v, 1: 1$ ), and stored for $72 \mathrm{~h}$ in dark. The solution was then transferred to $120 \mathrm{~mL}$ of ice water (containing $1 \mathrm{~mL} \mathrm{HCL}$ ) with a pipette. The precipitated lignin acetate was separated by centrifugation and washed twice with DI water, discarding all supernatants, and then air dried at room temperature for $48 \mathrm{~h}$ and then in a vacuum oven at $50{ }^{\circ} \mathrm{C}$ for an additional $24 \mathrm{~h} \mathrm{[21].}$

The molecular weights of the acetylated lignin samples were analyzed by GPC (LC-20 A, Shimadzu Co., Kyoto, Japan) with a RID to get weight-average (Mw) and number-weight (Mn) molecular weights and polydispersity index (PI, Mw/Mn). Lignin acetate (2 mg) was dissolved in $1 \mathrm{~mL}$ of tetrahydrofuran (THF). The KF-803 gel column $(300 \mathrm{~mm} \times 8.0 \mathrm{~mm})$ was calibrated with polystyrene standards (peak average molecular weights of 43,600 , $30,000,20,000,10,000,4050,2400 \mathrm{Da})$. THF was used as an eluent at a flow rate of 1 $\mathrm{mL} / \mathrm{min}$. The column temperature was $35^{\circ} \mathrm{C}$.

\subsection{Fourier Transform-Infrared (FT-IR) Spectroscopy Analysis}

FT-IR (FTIR-650, Tianjin GangDong Sci\&Tech Development Co., Ltd, Tianjin, China) was used to analyze the changes of lignin chemical bonds and functional groups after pretreatment. All samples were pressed by $\mathrm{KBr}$ prior to testing.

\subsection{Nuclear Magnetic Resonance (NMR) Spectroscopic Analyses of Lignin}

${ }^{31} \mathrm{P} \mathrm{NMR}$ and $2 \mathrm{D}{ }^{1} \mathrm{H}-{ }^{13} \mathrm{C}$ heterogeneous single quantum correlation (HSQC) NMR of lignin samples were analyzed using a Bruker AVIII $600 \mathrm{MHz}$ (Switzerland) spectrometer. For 31P NMR analysis, $25 \mathrm{mg}$ of dried lignin was dissolved in $400 \mu \mathrm{L}$ of anhydrous pyridine-d5/CDCl $3(1.6 / 1, v / v)$ solution. Then, $150 \mu \mathrm{L}$ of cyclohexanol $(4.0 \mathrm{mg} / \mathrm{mL}$, internal standard) and chromium (III) acetylacetonate $(3.6 \mathrm{mg} / \mathrm{mL}$, relaxation regent), prepared using anhydrous pyridine- $\mathrm{d} 5 / \mathrm{CDCl}_{3}$ solution, were mixed well with lignin solution and then added to a $75 \mu \mathrm{L}$ phosphitylating regent (2-chloro-4,4,5,5-tetramethyl1,2,3-dioxaphospholane, TMDP), which was shaken at room temperature for $1 \mathrm{~min}$, and then analyzed immediately $[26,46]$. The PULCON (pulse length-based concentration determination) method was applied to the phosphorylated lignin sample to collect 250 scans, and the spectrum was calibrated according to phosphorylation agent at $145.1 \mathrm{ppm}$.

For 2D-HSQC NMR experiments, $60 \mathrm{mg}$ of lignin were dissolved in $0.6 \mathrm{~mL}$ of dimethyl sulfoxide- $\mathrm{d}_{6} /$ pyridine- $\mathrm{d}_{5}$ (4:1) [21]. HSQC experiments were performed using the Bruker standard pulse program hsqcetgisisp2.2. Spectra were acquired using 40 scans, an interscan delay of $1 \mathrm{~s}$, a 12-ppm sweep width in F2 $(1 \mathrm{H}), 1024$ data points for an acquisition time of $85 \mathrm{~ms}$ and a 215-ppm sweep width in F1 (13C), and 512 increments with $50 \%$ nonuniform sampling density. Topspin 4.0.9 was used for interactive integration of the cross peaks after the central DMSO solvent peak was referenced at $\delta 13 \mathrm{C}, 39.5 \mathrm{ppm} ; \delta 1 \mathrm{H}, 2.5 \mathrm{ppm}$.

\subsection{Thermogravimetric (TG) Analysis}

Thermogravimetric studies were performed using a NETZSCH TG 209 F1 thermal analyzer made by the Shimadzu Company, Kyoto, Japan. The thermal decomposition characteristics of the lignin samples were determined with an HTG-3 thermal analyzer (TGA209 F1, NETZSCH Scientific Instruments Trading Ltd., Selb, Germany). A total of 5-10 $\mathrm{mg}$ of the samples were placed in an alumina crucible and heated from 30 to $800^{\circ} \mathrm{C}$, 
at heating rates of $10{ }^{\circ} \mathrm{C} / \mathrm{min}$. Nitrogen was used as an inert gas with a flow rate of $50 \mathrm{~mL} / \mathrm{min}[47,48]$.

\subsection{Differential Scanning Calorimetric (DSC) Analyses}

The lignin glass transition temperature $\mathrm{T}_{\mathrm{g}}$ was obtained through DSC analyses using a calorimetric system (DSC-0306, NETZSCH Scientific Instruments Trading Ltd., Selb, Germany). Lignin of $5-10 \mathrm{mg}$ ran at a heating rate of $10^{\circ} \mathrm{C} / \mathrm{min}$ between $40^{\circ} \mathrm{C}$ and $200{ }^{\circ} \mathrm{C}$, under nitrogen flow $(40 \mathrm{~mL} / \mathrm{min})$ [21].

\section{Conclusions}

This study reported that the rice straw hydrotropic lignin was successfully isolated from $p-\mathrm{TsOH}$ fractionation, then characterized comprehensively. The value of CDF indicated the fractionation severity. The hydrotropic rice straw lignin particle was in nanoscale. The PDI of hydrotropic lignin was higher than that of alkaline lignin. Compared with alkaline lignin, especially at low fractionation severities, the hydrotropic lignin has wellpreserved $\beta$-aryl linkage content, high reactivity, large molecular weight and low glass transition temperature, excellent for direct application in composites or catalytic valorization.

Author Contributions: C.Y.: Methodology, Investigation, Acquisition, Analysis, or Writing-original draft. M.W.: Methodology, Investigation, Analysis. Q.M.: Methodology, Investigation, Analysis, or interpretation of data. H.B.: Interpretation of data, Review \& Editing. J.C.: Supervision, Conceptualization, Design, Validation, Writing — review \& editing. Hao Ren: Software, Validation, Resources, Editing. H.D.: Project administration, Resources. All authors have read and agreed to the published version of the manuscript.

Funding: This research was funded by National Key R\&D Program of China, grant number 2019YFC1905903.

Institutional Review Board Statement: Not applicable.

Informed Consent Statement: Not applicable.

Data Availability Statement: The data presented in this study are available on request from the corresponding author.

Acknowledgments: The authors would like to acknowledge the financial support from National Key R\&D Program of China (Grant No. 2019YFC1905903). The authors also would like to acknowledge Jiesheng $\mathrm{Wu}$ (Nanjing Forestry University, NFU) for the rice straw material, Chen Su (NFU) and Chao Liu (Southeast University, Nanjing, China) for NMR analysis help, Huamin Zhai (NFU), Yunfeng Cao (NFU) and Weibin Wu (NFU) for allowing us using their lab equipment, and helpful discussion.

Conflicts of Interest: The authors declare no conflict of interest.

Sample Availability: Samples of the compounds are not available from the authors.

\section{References}

1. Gupta, G.K.; Shukla, P. Insights into the resources generation from pulp and paper industry wastes: Challenges, perspectives and innovations. Bioresour. Technol. 2020, 297, 122496. [CrossRef]

2. Morris, J. Recycle, Bury, or Burn Wood Waste Biomass? LCA Answer Depends on Carbon Accounting, Emissions Controls, Displaced Fuels, and Impact Costs. J. Ind. Ecol. 2017, 21, 844-856. [CrossRef]

3. Wu, J.; Dong, L.; Liu, B.; Xing, D.; Zhou, C.; Wang, Q.; Wu, X.; Feng, L.; Cao, G. A novel integrated process to convert cellulose and hemicellulose in rice straw to biobutanol. Environ. Res. 2020, 186, 109580. [CrossRef]

4. Schutyser, W.; Renders, T.; Van den Bosch, S.; Koelewijn, S.F.; Beckham, G.T.; Sels, B.F. Chemicals from lignin: An interplay of lignocellulose fractionation, depolymerisation, and upgrading. Chem. Soc. Rev. 2018, 47, 852-908. [CrossRef]

5. Dusselier, M.; Mascal, M.; Sels, B.F. Top Chemical Opportunities from Carbohydrate Biomass: A Chemist's View of the Biorefinery. In Selective Catalysis for Renewable Feedstocks and Chemicals; Nicholas, K.M., Ed.; Springer International: Cham, Switzerland, 2014; Volume 353, pp. 1-40.

6. Behling, R.; Valange, S.; Chatel, G. Heterogeneous catalytic oxidation for lignin valorization into valuable chemicals: What results? What limitations? What trends? Green Chem. 2016, 18, 1839-1854. [CrossRef] 
7. Pan, X.; Gilkes, N.; Kadla, J.; Pye, K.; Saka, S.; Gregg, D.; Ehara, K.; Xie, D.; Lam, D.; Saddler, J. Bioconversion of hybrid poplar to ethanol and co-products using an organosolv fractionation process: Optimization of process yields. Biotechnol. Bioeng. 2006, 94, 851-861. [CrossRef]

8. Singh, G.; Arya, S.K. A review on management of rice straw by use of cleaner technologies: Abundant opportunities and expectations for Indian farming. J. Clean. Prod. 2020, 291, 125278. [CrossRef]

9. Cheng, J.; Leu, S.-Y.; Zhu, J.Y.; Jeffries, T.W. Ethanol production from non-detoxified whole slurry of sulfite-pretreated empty fruit bunches at a low cellulase loading. Bioresour. Technol. 2014, 164, 331-337. [CrossRef] [PubMed]

10. Lim, W.-L.; Gunny, A.A.N.; Kasim, F.H.; AiNashef, I.M.; Arbain, D. Alkaline deep eutectic solvent: A novel green solvent for lignocellulose pulping. Cellulose 2019, 26, 4085-4098. [CrossRef]

11. Jahan, M.S.; Sutradhar, S.; Rahman, M.M.; Quaiyyum, M.A. Fractionation of rice straw for producing dissolving pulp in biorefinery concept. Nord. Pulp Pap. Res. J. 2015, 30, 562-567.

12. Nowakowski, D.J.; Jones, J.M. Uncatalysed and potassium-catalysed pyrolysis of the cell-wall constituents of biomass and their model compounds. J. Anal. Appl. Pyrolysis 2008, 83, 12-25. [CrossRef]

13. Moiseenko, K.V.; Glazunova, O.A.; Savinova, O.S.; Vasina, D.V.; Zherebker, A.Y.; Kulikova, N.A.; Nikolaev, E.N.; Fedorova, T.V. Relation between lignin molecular profile and fungal exo-proteome during kraft lignin modification by Trametes hirsuta LE-BIN 072. Bioresour. Technol. 2021, 335, 125229. [CrossRef]

14. Lahtinen, M.H.; Mikkila, J.; Mikkonen, K.S.; Kilpelainen, I. Kraft Process-Formation of Secoisolariciresinol Structures and Incorporation of Fatty Acids in Kraft Lignin. J. Agric. Food Chem. 2021, 69, 5955-5965. [CrossRef]

15. Hodgdon, T.K.; Kaler, E.W. Hydrotropic solutions. Curr. Opin. Colloid Interface Sci. 2007, 12, 121-128.

16. Chen, H.; Jiang, B.; Wu, W.; Jin, Y. Comparison of enzymatic saccharification and lignin structure of masson pine and poplar pretreated by p-Toluenesulfonic acid. Int. J. Biol. Macromol. 2020, 151, 861-869. [CrossRef] [PubMed]

17. Wang, W.; Gu, F.; Zhu, J.Y.; Sun, K.; Cai, Z.; Yao, S.; Wu, W.; Jin, Y. Fractionation of herbaceous biomass using a recyclable hydrotropic p-toluenesulfonic acid $(\mathrm{p}-\mathrm{TsOH}) /$ choline chloride $(\mathrm{ChCl})$ solvent system at low temperatures. Ind. Crops Prod. 2020, 150, 112423. [CrossRef]

18. Chen, L.; Dou, J.; Ma, Q.; Li, N.; Wu, R.; Bian, H.; Yelle, D.J.; Vuorinen, T.; Fu, S.; Pan, X.; et al. Rapid and near-complete dissolution of wood lignin at $\leq 80$ degrees $C$ by a recyclable acid hydrotrope. Sci. Adv. 2017, 3, e1701735. [CrossRef]

19. Kunz, W.; Holmberg, K.; Zemb, T. Hydrotropes. Curr. Opin. Colloid Interface Sci. 2016, 22, 99-107.

20. Ma, Q.; Chen, L.; Wang, R.; Yang, R.; Zhu, J.Y. Direct production of lignin nanoparticles (LNPs) from wood using p-toluenesulfonic acid in an aqueous system at 80 degrees C: Characterization of LNP morphology, size, and surface charge. Holzforschung 2018, 72 , 933-942. [CrossRef]

21. Cheng, J.; Hirth, K.; Ma, Q.; Zhu, J.; Wang, Z.; Zhu, J.Y. Toward Sustainable and Complete Wood Valorization by Fractionating Lignin with Low Condensation Using an Acid Hydrotrope at Low Temperatures ( $\leq 80$ degrees C). Ind. Eng. Chem. Res. 2019, 58, 7063-7073. [CrossRef]

22. Wang, Z.; Qiu, S.; Hirth, K.; Cheng, J.; Wen, J.; Li, N.; Fang, Y.; Pan, X.; Zhu, J.Y. Preserving Both Lignin and Cellulose Chemical Structures: Flow-Through Acid Hydrotropic Fractionation at Atmospheric Pressure for Complete Wood Valorization. Acs Sustain. Chem. Eng. 2019, 7, 10808-10820. [CrossRef]

23. Chen, L.; Zhu, J.Y.; Baez, C.; Kitin, P.; Elder, T. Highly thermal-stable and functional cellulose nanocrystals and nanofibrils produced using fully recyclable organic acids. Green Chem. 2016, 18, 3835-3843. [CrossRef]

24. Ma, Q.; Zhu, J.; Gleisner, R.; Yang, R.; Zhu, J.Y. Valorization of Wheat Straw Using a Recyclable Hydrotrope at Low Temperatures ( $\leq 90$ degrees C). Acs Sustain. Chem. Eng. 2018, 6, 14480-14489. [CrossRef]

25. Leu, S.Y.; Zhu, J.Y.; Gleisner, R.; Sessions, J.; Marrs, G. Robust enzymatic saccharification of a Douglas-fir forest harvest residue by SPORL. Biomass Bioenergy 2013, 59, 393-401.

26. Su, C.; Hirth, K.; Liu, Z.; Cao, Y.; Zhu, J.Y. Acid hydrotropic fractionation of switchgrass at atmospheric pressure using maleic acid in comparison with p-TsOH: Advantages of lignin esterification. Ind. Crops Prod. 2021, 159, 113017. [CrossRef]

27. Bian, H.; Dong, M.; Chen, L.; Zhou, X.; Wang, R.; Jiao, L.; Ji, X.; Dai, H. On-Demand Regulation of Lignocellulosic Nanofibrils Based on Rapid Fractionation Using Acid Hydrotrope: Kinetic Study and Characterization. ACS Sustain. Chem. Eng. 2020, 8 , 9569-9577. [CrossRef]

28. Deng, J.; Sun, S.-F.; Zhu, E.-Q.; Yang, J.; Yang, H.-Y.; Wang, D.-W.; Ma, M.-G.; Shi, Z.-J. Sub-micro and nano-lignin materials: Small size and rapid progress. Ind. Crops Prod. 2021, 164, 113412. [CrossRef]

29. Moradi, S.; Shayesteh, K.; Behbudi, G. Preparation and characterization of biodegradable lignin-sulfonate nanoparticles using the microemulsion method to enhance the acetylation efficiency of lignin-sulfonate. Int. J. Biol. Macromol. 2020, 160, 632-641. [CrossRef]

30. Freitas, F.M.C.; Cerqueira, M.A.; Gonçalves, C.; Azinheiro, S.; Garrido-Maestu, A.; Vicente, A.A.; Pastrana, L.M.; Teixeira, J.A.; Michelin, M. Green synthesis of lignin nano- and micro-particles: Physicochemical characterization, bioactive properties and cytotoxicity assessment. Int. J. Biol. Macromol. 2020, 163, 1798-1809. [CrossRef]

31. Mou, H.Y.; Heikkilä, E.; Fardim, P. Topochemistry of alkaline, alkaline-peroxide and hydrotropic pretreatments of common reed to enhance enzymatic hydrolysis efficiency. Bioresour. Technol. 2013, 150, 36-41. [CrossRef] [PubMed]

32. Pereira Araujo, L.C.; Yamaji, F.M.; Lima, V.H.; Botaro, V.R. Kraft lignin fractionation by organic solvents: Correlation between molar mass and higher heating value. Bioresour. Technol. 2020, 314, 123757. [CrossRef] [PubMed] 
33. Wen, J.-L.; Sun, S.-N.; Yuan, T.-Q.; Xu, F.; Sun, R.-C. Fractionation of bamboo culms by autohydrolysis, organosolv delignification and extended delignification: Understanding the fundamental chemistry of the lignin during the integrated process. Bioresour. Technol. 2013, 150, 278-286. [CrossRef] [PubMed]

34. Del Rio, J.C.; Rencoret, J.; Prinsen, P.; Martinez, A.T.; Ralph, J.; Gutierrez, A. Structural Characterization of Wheat Straw Lignin as Revealed by Analytical Pyrolysis, 2D-NMR, and Reductive Cleavage Methods. J. Agric. Food Chem. 2012, 60, 5922-5935. [CrossRef] [PubMed]

35. Yelle, D.J.; Ralph, J.; Frihart, C.R. Characterization of nonderivatized plant cell walls using high-resolution solution-state NMR spectroscopy. Magn. Reson. Chem. 2008, 46, 508-517. [CrossRef]

36. Liu, C.; Wang, X.; Lin, F.; Zhang, H.; Xiao, R. Structural elucidation of industrial bioethanol residual lignin from corn stalk: A potential source of vinyl phenolics. Fuel Process. Technol. 2018, 169, 50-57. [CrossRef]

37. Zeng, J.; Helms, G.L.; Gao, X.; Chen, S. Quantification of Wheat Straw Lignin Structure by Comprehensive NMR Analysis. J. Agric. Food Chem. 2013, 61, 10848-10857. [CrossRef]

38. Li, N.; Li, Y.; Yoo, C.G.; Yang, X.; Lin, X.; Ralph, J.; Pan, X. An uncondensed lignin depolymerized in the solid state and isolated from lignocellulosic biomass: A mechanistic study. Green Chem. 2018, 20, 4224-4235. [CrossRef]

39. Yuan, T.Q.; Sun, S.N.; Xu, F.; Sun, R.C. Characterization of Lignin Structures and Lignin-Carbohydrate Complex (LCC) Linkages by Quantitative C-13 and 2D HSQC NMR Spectroscopy. J. Agric. Food Chem. 2011, 59, 10604-10614. [CrossRef]

40. Jiang, B.; Zhang, Y.; Gu, L.; Wu, W.; Zhao, H.; Jin, Y. Structural elucidation and antioxidant activity of lignin isolated from rice straw and alkalioxygen black liquor. Int. J. Biol. Macromol. 2018, 116, 513-519. [CrossRef]

41. Shuai, L.; Amiri, M.T.; Questell-Santiago, Y.M.; Heroguel, F.; Li, Y.; Kim, H.; Meilan, R.; Chapple, C.; Ralph, J.; Luterbacher, J.S. Formaldehyde stabilization facilitates lignin monomer production during biomass depolymerization. Science 2016, 354, 329-333. [CrossRef]

42. Yang, H.; Xie, Y.; Zheng, X.; Pu, Y.; Huang, F.; Meng, X.; Wu, W.; Ragauskas, A.; Yao, L. Comparative study of lignin characteristics from wheat straw obtained by soda-AQ and kraft pretreatment and effect on the following enzymatic hydrolysis process. Bioresour. Technol. 2016, 207, 361-369. [CrossRef]

43. Del Rio, J.C.; Gutierrez, A.; Hernando, M.; Landin, P.; Romero, J.; Martinez, A.T. Determining the influence of eucalypt lignin composition in paper pulp yield using Py-GC/MS. J. Anal. Appl. Pyrolysis 2005, 74, 110-115. [CrossRef]

44. Gutierrez, A.; Rodriguez, I.M.; del Rio, J.C. Chemical characterization of lignin and lipid fractions in industrial hemp bast fibers used for manufacturing high-quality paper pulps. J. Agric. Food Chem. 2006, 54, 2138-2144. [CrossRef]

45. Min, D.; Yang, C.; Shi, R.; Jameel, H.; Chiang, V.; Chang, H. The elucidation of the lignin structure effect on the cellulase-mediated saccharification by genetic engineering poplars (Populus nigra L. x Populus maximowiczii A.). Biomass Bioenergy 2013, 58, 52-57. [CrossRef]

46. Su, Y.; Huang, C.; Lai, C.; Yong, Q. Green solvent pretreatment for enhanced production of sugars and antioxidative lignin from poplar. Bioresour. Technol. 2021, 321, 124471. [CrossRef] [PubMed]

47. Santos, V.O.; Queiroz, L.S.; Araujo, R.O.; Ribeiro, F.C.P.; Guimarães, M.N.; da Costa, C.E.F.; Chaar, J.S.; de Souza, L.K.C. Pyrolysis of acai seed biomass: Kinetics and thermodynamic parameters using thermogravimetric analysis. Bioresour. Technol. Rep. 2020, 12, 100553. [CrossRef]

48. Ninduangdee, P.; Kuprianov, V.I.; Cha, E.Y.; Kaewrath, R.; Youngyuen, P.; Atthawethworawuth, W. Thermogravimetric Studies of Oil Palm Empty Fruit Bunch and Palm Kernel Shell: TG/DTG Analysis and Modeling. Energy Procedia 2015, 79, 453-458. [CrossRef] 